\title{
Diagnostic Accuracy of Fluorine-18-Fluorodeoxyglucose Positron Emission Tomography in the Evaluation of the Primary Tumor in Patients with Cholangiocarcinoma: A Meta-Analysis
}

\author{
Salvatore Annunziata, ${ }^{1}$ Carmelo Caldarella, ${ }^{1}$ Daniele Antonio Pizzuto, ${ }^{1}$ \\ Federica Galiandro, ${ }^{2}$ Ramin Sadeghi, ${ }^{3}$ Luca Giovanella, ${ }^{4}$ and Giorgio Treglia ${ }^{4}$ \\ ${ }^{1}$ Institute of Nuclear Medicine, Catholic University of the Sacred Heart, Largo Agostino Gemelli 8, 00168 Rome, Italy \\ ${ }^{2}$ Postgraduate School of General Surgery, Catholic University of the Sacred Heart, Largo Agostino Gemelli 8, \\ 00168 Rome, Italy \\ ${ }^{3}$ Nuclear Medicine Research Center, Mashhad University of Medical Sciences, Daneshgah Avenue, Mashhad 9179817317, Iran \\ ${ }^{4}$ Department of Nuclear Medicine and PET/CT Center, Oncology Institute of Southern Switzerland, Via Ospedale 12, \\ 6500 Bellinzona, Switzerland
}

Correspondence should be addressed to Salvatore Annunziata; salvatoreannunziata@live.it

Received 15 February 2014; Accepted 15 April 2014; Published 13 May 2014

Academic Editor: Letterio S. Politi

Copyright (C) 2014 Salvatore Annunziata et al. This is an open access article distributed under the Creative Commons Attribution License, which permits unrestricted use, distribution, and reproduction in any medium, provided the original work is properly cited.

\begin{abstract}
Objective. To meta-analyze published data about the diagnostic accuracy of fluorine-18-fluorodeoxyglucose $\left({ }^{18}\right.$ F-FDG) positron emission tomography (PET) or PET/computed tomography (PET/CT) for primary tumor evaluation in patients with cholangiocarcinoma (CCa). Methods. A comprehensive literature search of studies published through December 31, 2013, was performed. Pooled sensitivity and specificity were calculated on a per patient based analysis. Subgroup analyses considering the device used (PET versus $\mathrm{PET} / \mathrm{CT}$ ) and the localization of the primary tumor (intrahepatic cholangiocarcinoma (IH-CCa), extrahepatic cholangiocarcinoma (EH-CCa), and hilar cholangiocarcinoma $(\mathrm{H}-\mathrm{CCa})$ ) were carried out. Results. Twenty-three studies including 1232 patients were included in the meta-analysis. Pooled sensitivity and specificity of ${ }^{18} \mathrm{~F}-\mathrm{FDG}$-PET or PET/CT were $81 \%$ and $82 \%$, respectively. Pooled sensitivity and specificity, respectively, were $80 \%$ and $89 \%$ for PET, $82 \%$ and $75 \%$ for PET/CT, 95\% and $83 \%$ for IH-CCa, $84 \%$ and $95 \%$ for $\mathrm{H}-\mathrm{CCa}$, and $76 \%$ and $74 \%$ for EH-CCa. Conclusions. ${ }^{18} \mathrm{~F}-\mathrm{FDG}-\mathrm{PET}$ and PET/CT were demonstrated to be accurate diagnostic imaging methods for primary tumor evaluation in patients with CCa. These tools have a better diagnostic accuracy in patients with IH-CCa than in patients with EH-CCa. Further studies are needed to evaluate the accuracy of ${ }^{18}$ F-FDG-PET or $\mathrm{PET} / \mathrm{CT}$ in patients with $\mathrm{H}-\mathrm{CC}$.
\end{abstract}

\section{Introduction}

Cholangiocarcinoma ( $\mathrm{CCa}$ ) is a malignant tumor arising from the epithelium of the bile ducts and is usually classified by anatomical and clinical criteria into intrahepatic cholangiocarcinoma ( $\mathrm{IH}-\mathrm{CCa})$, hilar cholangiocarcinoma ( $\mathrm{H}-\mathrm{CCa})$, and extrahepatic cholangiocarcinoma (EH-CCa) [1]. CCa has a poor prognosis and surgical resection with appropriate lymph node dissection is advocated as the curative approach in some patients [2]. Consequently, accurate evaluation and staging are critical to provide indication to surgery and to avoid unnecessary surgical interventions [3].

Several diagnostic tools have been used in this setting, including ultrasonography (US), computed tomography (CT), magnetic resonance (MR), endoscopic retrograde cholangiopancreatography (ERCP), and percutaneous transhepatic cholangiography (PTC).

Fluorine-18-fluorodeoxyglucose $\left({ }^{18} \mathrm{~F}\right.$-FDG $)$ positron emission tomography (PET) and PET/CT have been proposed as noninvasive imaging methods to assess the disease 
extent in cancer patients [4]. Since ${ }^{18}$ F-FDG is a glucose analogue, this radiopharmaceutical may be very useful in detecting malignant lesions which usually present high glucose metabolism. Hybrid PET/CT device allows enhanced detection and characterization of neoplastic lesions, by combining the functional data obtained by PET with morphological data obtained by CT [4].

Several studies have assessed the diagnostic accuracy of ${ }^{18}$ F-FDG-PET or PET/CT in the evaluation of primary tumor in patients with CCa, reporting different values of sensitivity and specificity. The purpose of our study is to meta-analyze published data on the diagnostic accuracy of ${ }^{18}$ F-FDG-PET or $\mathrm{PET} / \mathrm{CT}$ in the evaluation of primary tumor in patients with $\mathrm{CCa}$, in order to provide more evidence-based data and to address further studies in this setting.

\section{Materials and Methods}

2.1. Search Strategy. A comprehensive computer literature search of PubMed/MEDLINE and Embase databases was carried out to find relevant published articles concerning the evaluation of primary tumor in patients with CCa. We used a search algorithm based on a combination of terms ("PET" or "positron emission tomography") and ("cholangiocarcinoma" or "cholangiocellular" or "cholangio*" or "biliar" or "biliary" or "bile" or "Klatskin"). Only articles in English language were considered. The search was performed from inception to December 31, 2013. To expand our search, references of the retrieved articles were also screened for additional studies.

2.2. Study Selection. Studies or subsets in studies investigating the role of ${ }^{18}$ F-FDG-PET or PET/CT in the evaluation of primary CCa were eligible for inclusion. Case reports, small case series, review articles, letters, editorials, and conference proceedings were excluded. The following inclusion criteria were applied to select studies for this meta-analysis:

(1) original studies in which ${ }^{18}$ F-FDG-PET or PET/CT were performed in patients with CCa or suspicious $\mathrm{CCa}$;

(2) a sample size of at least ten patients with CCa or suspicious CCa;

(3) sufficient data to reassess sensitivity and specificity of ${ }^{18}$ F-FDG-PET or PET/CT in detecting the primary tumor in patients with $\mathrm{CCa}$;

(4) no data overlap.

Three researchers (SA, DAP, and CC) independently reviewed titles and abstracts of the retrieved articles, applying the above-mentioned selection criteria. Articles were rejected if they were clearly ineligible. The same three researchers then independently evaluated the full-text version of the included articles to determine their eligibility for inclusion.

2.3. Data Extraction. Information about basic study (authors, year of publication, and country of origin), study design (prospective or retrospective), patients' characteristics (number of patients with biliary ducts lesions performing ${ }^{18} \mathrm{~F}$ FDG-PET or PET/CT, mean age, and gender), and technical aspects (injected activity of ${ }^{18}$ F-FDG and time between injection and image acquisition) was collected.

Each study was analyzed to retrieve the number of truepositive (TP), true-negative (TN), false-positive (FP), and false-negative (FN) findings of ${ }^{18} \mathrm{~F}$-FDG-PET or PET/CT in patients with $\mathrm{CCa}$ or suspicious $\mathrm{CCa}$, according to the reference standard. Only studies providing such complete information were finally included in the meta-analysis.

2.4. Quality Assessment. The 2011 Oxford Center for Evidence-Based Medicine checklist for diagnostic studies was used for quality assessment of the included studies. This checklist has 5 major parts as follows: representative spectrum of the patients, consecutive patient recruitment, ascertainment of the gold standard regardless of the index test results, independent blind comparison between the gold standard and index test results, and enough explanation of the test to permit replication.

2.5. Statistical Analysis. Sensitivity and specificity of ${ }^{18} \mathrm{~F}-$ FDG-PET and PET/CT in the evaluation of primary CCa were obtained from the individual studies, on a per patientbased analysis. We considered as positive a biliary ducts lesion with increased uptake of ${ }^{18}$ F-FDG, according to the criteria reported by the different authors. When a positive lesion was histologically confirmed as malignant, this was considered a TP lesion, whereas a histologically confirmed benign lesion was considered as a FP lesion. We considered as negative a lesion with no uptake of ${ }^{18}$ F-FDG: when the lesion was histologically confirmed as malignant, this was considered as FN lesion, whereas a histologically confirmed benign lesion was considered as a TN lesion.

Sensitivity was determined according to the following formula: $\mathrm{TP} /(\mathrm{TP}+\mathrm{FN})$; specificity was determined according to this following formula: $\mathrm{TN} /(\mathrm{TN}+\mathrm{FP})$. Statistical pooling of the data was performed by means of a random effects model. Pooled data are presented with $95 \%$ confidence intervals (95\% CI). Heterogeneity between studies was assessed by an $I^{2}$ index. A summary receiving operator characteristics (ROC) curve was obtained for selected studies and area under the curve (AUC) was calculated to assess the overall accuracy of ${ }^{18}$ F-FDG-PET and PET/CT.

Subsequently, subgroup analyses were also performed, calculating the pooled sensitivity and specificity of ${ }^{18}$ F-FDG$\mathrm{PET}$ and $\mathrm{PET} / \mathrm{CT}$ in three different groups of primary $\mathrm{CCa}$ (IH-CCa, EH-CCa, and $\mathrm{H}-\mathrm{CCa}$ ) and in two groups based on the different device used (PET or PET/CT).

For publication bias evaluation, funnel plots, Egger's regression intercept, and Duval and Tweedie's method were used [5].

Statistical analyses were performed using Meta-DiSc statistical software version 1.4. 


\section{Results}

3.1. Literature Search. The comprehensive computer literature search from PubMed/MEDLINE and Embase databases revealed 449 articles. Reviewing titles and abstracts, 406 records were excluded as reviews, editorials or letters, case reports or case series, or no direct link with the main subject. Twenty articles were excluded due to absence of data to reassess the pooled sensitivity or specificity of ${ }^{18} \mathrm{~F}$-FDG-PET or PET/CT in evaluating the primary tumor in patients with CCa or suspicious CCa. Finally, 23 articles including 1232 patients were selected and were eligible for the meta-analysis [1-3, 6-25]; no additional studies were found screening the references of these articles (Figure 1). The characteristics of the included studies are presented in Tables 1, 2,3 and 4.

3.2. Qualitative Analysis (Systematic Review). Using the database search, 23 original articles written over the past 12 years were selected [1-3, 6-25]. About the study design, 7 of these studies were prospective $[6,7,13,14,17-19]$ and 12 were retrospective $[1-3,9,12,15,16,20-22,24,25]$ and in 4 articles this information was not provided $[8,10,11,23]$.

Ten studies used hybrid PET/CT [1-3, 11, 13, 18, 19, 2123], whereas thirteen studies used PET only [6-10, 12, 14$17,20,24,25]$. Heterogeneous technical aspects between the included studies were found (Table 2). PET image analysis was performed by using qualitative criteria (visual analysis) in all the included studies [1-3, 6-25] and adjunctive semiquantitative criteria (based on the calculation of the standardized uptake value (SUV)) in 19 articles $[1-3,6-9,11,13,15,16,18$ 25]. One study used quantitative criteria (based on blood sampling and the Gjedde-Patlak linearization procedure) [14].

The reference standard used to validate the ${ }^{18} \mathrm{~F}-\mathrm{FDG}$ PET or PET/CT findings in the included studies was quite different (Table 4). The results of the quality assessment of the studies included in this systematic review, according to the 2011 Oxford Center for Evidence-Based Medicine checklist for diagnostic studies, are shown in Table 4.

3.3. Quantitative Analysis (Meta-Analysis). The diagnostic accuracy values of ${ }^{18} \mathrm{~F}$-FDG-PET and PET/CT in the 23 studies included in the meta-analysis are presented in Figures $2-4$. All the 23 studies had sufficient data to calculate the pooled sensitivity [1-3, 6-25], whereas only 13 studies $[1,7$, $10-16,18,20-22]$ provided information about TN and FP lesions, thus allowing assessment of pooled specificity.

Sensitivity and specificity values of ${ }^{18}$ F-FDG-PET or $\mathrm{PET} / \mathrm{CT}$ on a per patient-based analysis ranged from 59 to $100 \%$ and from 63 to $100 \%$, with pooled estimates of $81 \%$ (95\% CI: 78-83\%) and 82\% (95\% CI: 75-87\%), respectively. The area under the summary ROC curve was 0.89 . The included studies showed statistical heterogeneity in their estimate of sensitivity $\left(I^{2}: 63.7 \%\right)$.

Egger's regression intercepts for sensitivity and specificity pooling were 1.9 (95\% CI: 0.3 to $3.5, P=0.02$ ) and -0.7 (95\% CI: -2.4 to $0.9, P=0.35$ ), respectively. Applying Duval and Tweedie's method, the funnel plot of sensitivity and specificity reached symmetry and the adjusted sensitivity and specificity decreased $2.4 \%$ and increased $1.8 \%$, respectively (Figure 2).

To reduce the heterogeneity, subgroup analyses considering the different device used (PET or PET/CT) were performed (Figure 4). In studies in which ${ }^{18}$ F-FDG-PET was used, values of sensitivity (thirteen eligible studies) and specificity (seven eligible studies) on a per patient-based analysis ranged from 60 to $95 \%$ and from 67 to $95 \%$, respectively, with pooled estimates of $80 \%$ (95\% CI: $76-83 \%$ ) and $89 \%$ (95\% CI: 80-95\%), respectively. Statistical heterogeneity was found only in their estimate of sensitivity $\left(I^{2}: 63 \%\right)$. The area under the ROC curve was 0.92 .

In studies in which hybrid ${ }^{18} \mathrm{~F}$-FDG-PET/CT was used, values of sensitivity (ten eligible studies) and specificity (six eligible studies) on a per patient-based analysis ranged from 59 to $100 \%$ and from 63 to $100 \%$, respectively, with pooled estimates of $82 \%$ (95\% CI: 78-85\%) and 75\% (95\% CI: 65$84 \%)$, respectively. Statistical heterogeneity was found only in their estimate of sensitivity $\left(I^{2}: 67 \%\right)$. The area under the ROC curve was 0.81 .

Finally, subgroup analyses considering different anatomic sites of $\mathrm{CCa}$ (IH-CCa, EH-CCa, and H-CCa) were carried out (Figure 3). In patients with IH-CCa, values of sensitivity (nine eligible studies) and specificity (five eligible studies) on a per patient-based analysis ranged from 91 to $100 \%$ and from 80 to $100 \%$, respectively, with pooled estimates of $95 \%$ (95\% CI: 91$98 \%$ ) and $83 \%$ (95\% CI: 64-94\%), respectively. No statistical heterogeneity was found, among the included studies, in both the estimate of sensitivity and the estimate of specificity $\left(I^{2}\right.$ : $0 \%)$. The area under the ROC curve was 0.95 .

In patients with EH-CCA, values of sensitivity (twelve eligible studies) and specificity (seven eligible studies) on a per patient-based analysis ranged from 52 to $92 \%$ and from 33 to $100 \%$, respectively, with pooled estimates of $76 \%$ (95\% CI: $71-80 \%)$ and $74 \%$ (95\% CI: 58-87\%), respectively. Statistical heterogeneity was found only in their estimate of sensitivity $\left(I^{2}: 61 \%\right)$. The area under the ROC curve was 0.82 .

In patients with $\mathrm{H}$-CCA, values of sensitivity (eight eligible studies) and specificity (three eligible studies) on a per patient-based analysis ranged from 59 to $100 \%$ and from 93 to $100 \%$, respectively, with pooled estimates of $84 \%$ (95\% CI: 76-89\%) and 95\% (95\% CI: 82-99\%), respectively. No significant statistical heterogeneity was found in their estimate of sensitivity $\left(I^{2}: 48 \%\right)$ and specificity $\left(I^{2}: 0 \%\right)$. The area under the ROC curve was 0.98 .

\section{Discussion}

To the best of our knowledge, this meta-analysis is the first to evaluate the diagnostic accuracy of ${ }^{18} \mathrm{~F}$-FDG-PET or PET/CT in the evaluation of primary tumor in patients with $\mathrm{CCa}$ [26]. Several studies have used ${ }^{18} \mathrm{~F}$-FDG-PET or PET/CT in this setting reporting different values of sensitivity and specificity. However, many of these studies have limited power, analyzing only relatively small numbers of patients. In order to derive more robust estimates of the diagnostic accuracy of ${ }^{18} \mathrm{~F}$-FDGPET or PET/CT in this setting we pooled published studies. 


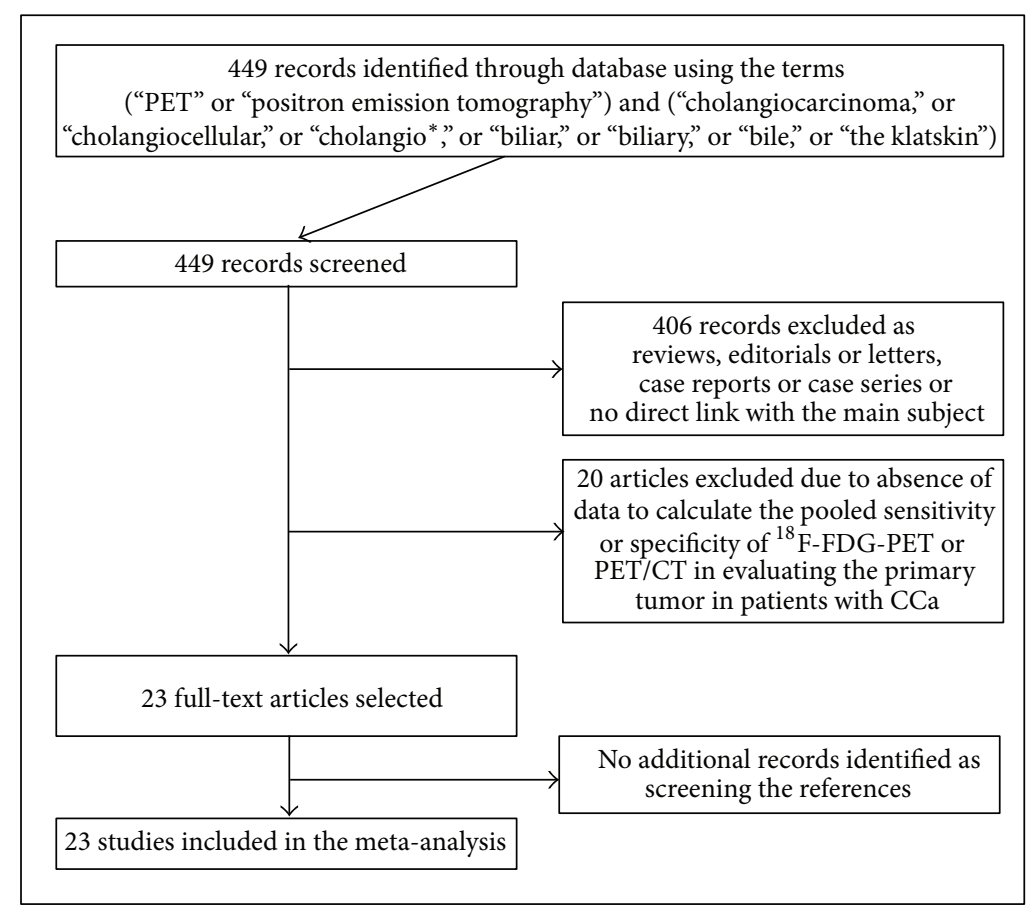

FIgURE 1: Plot of the literature search.

A systematic review process was adopted in ascertaining studies, thereby avoiding selection bias.

Pooled results of our meta-analysis indicate that ${ }^{18} \mathrm{~F}$ FDG-PET or PET/CT have a good sensitivity (81\%) and specificity $(82 \%)$ in the evaluation of primary tumor in patients with CCa. Furthermore, the value of the AUC (0.89) demonstrates that ${ }^{18}$ F-FDG-PET or PET/CT are accurate diagnostic methods in this setting. Considering patients with all anatomical localizations of primary CCa, independently of the device used (PET or PET/CT), significant heterogeneity between the studies in their estimate of sensitivity was found $\left(I^{2}: 63.7 \%\right)$. In order to reduce possible source of heterogeneity, subgroup analyses considering different device used (PET or PET/CT) and patients with different anatomical localizations (IH-, H-, and EH-CCa) were performed.

These subgroup analyses provide differences in the diagnostic accuracy data for various anatomical localizations. ${ }^{18}$ F-FDG-PET and PET/CT seem to be more sensitive and specific in the evaluation of primary tumor in patients with $\mathrm{IH}-\mathrm{CCA}$ than in patients with H-CCA and EH-CCA.

In particular ${ }^{18} \mathrm{~F}$-FDG-PET and PET/CT have a moderate diagnostic accuracy in evaluating primary $\mathrm{EH}-\mathrm{CCa}$ (sensitivity of $76 \%$ and specificity of $74 \%$ ). In this setting, sensitivity and specificity of ${ }^{18}$ F-FDG-PET and PET/CT may be affected by FN (due to the confounding anatomical localization of extrahepatic bile ducts) and FP (due to inflammation of extrahepatic bile ducts). Larger use of hybrid PET/CT and, consequently, further studies about the role of PET/CT in evaluation of primary tumour in patients with EH-CCA may improve these results.

Conversely, the diagnostic accuracy of ${ }^{18}$ F-FDG-PET and PET/CT in primary IH-CCA (sensitivity of 95\% and specificity of $83 \%$ ) seems to be better than in the other anatomical localizations of primary CCa. Possible explanations are the easier individuation of illness in the liver parenchyma and the small number of FP cases (intrahepatic noncancerous disease positive with ${ }^{18}$ F-FDG-PET). Further studies are needed to evaluate if different histological types of IH-CCA (nodular or mass-forming type, infiltrating type, and intraluminal type) could cause different diagnostic accuracy of ${ }^{18}$ F-FDG-PET and PET/CT in this setting.

Finally, the diagnostic accuracy of ${ }^{18}$ F-FDG-PET and $\mathrm{PET} / \mathrm{CT}$ in evaluating primary $\mathrm{H}-\mathrm{CCa}$ is good (sensitivity of $84 \%$ and specificity of $95 \%)$. Nevertheless, we cannot exclude that the low number of the included studies in this subgroup analysis may have influenced the results. FP findings (due to the presence of ${ }^{18}$ F-FDG-avid lymph nodes in the hepatic hilum) and FN results (due to the difficult anatomical localization of the hepatic hilum) should be considered. More studies are needed to further evaluate sensitivity and specificity of ${ }^{18}$ F-FDG-PET and PET/CT in primary $\mathrm{H}-\mathrm{CCa}$.

However, performing these subgroup analyses has been useful in demonstrating that the anatomical localization of primary tumor ( $\mathrm{IH}-\mathrm{CCa}, \mathrm{EH}-\mathrm{CCa}$, or H-CCA) is a source of heterogeneity among the studies. In fact, no significant heterogeneity was found in the subgroup analyses performed, except in the calculation of pooled sensitivity of ${ }^{18}$ F-FDG$\mathrm{PET}$ or PET/CT in primary EH-CCA.

Pooled sensitivity is similar in the subgroup analyses regarding different device used (80\% for PET and $82 \%$ for PET/CT, resp.). Nevertheless, heterogeneity was found in these groups, in particular for the calculation of pooled sensitivity, suggesting that, beyond the device used, other 


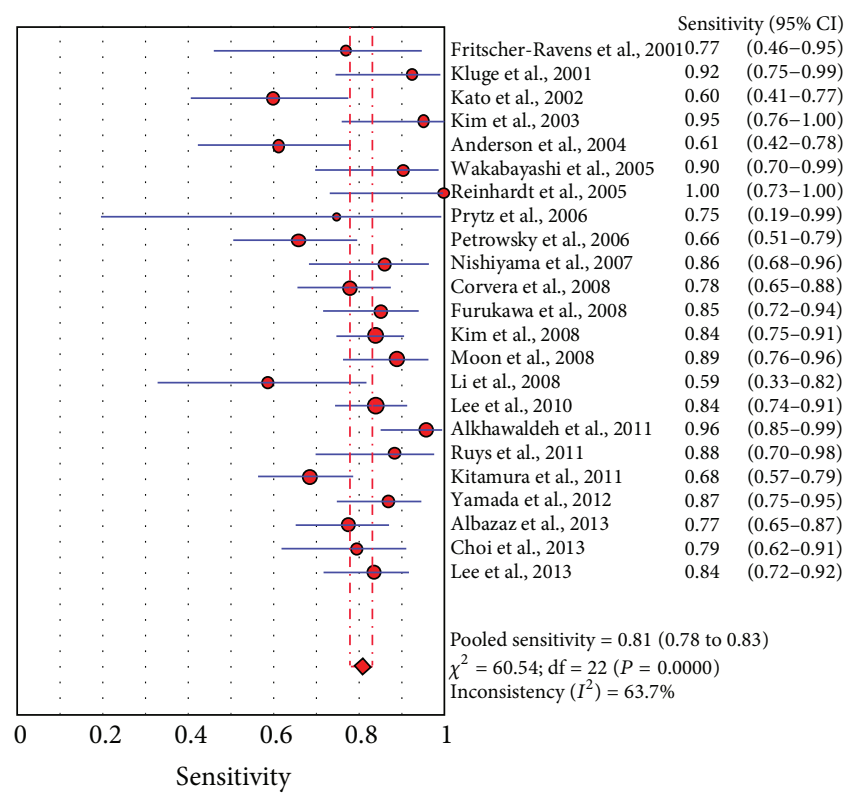

(a)

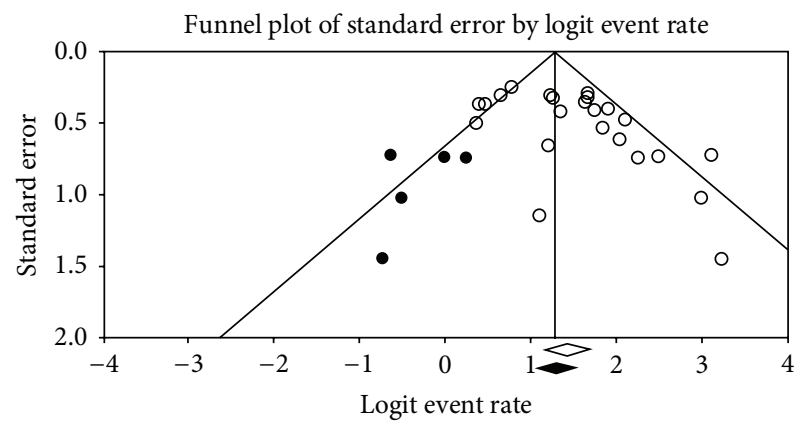

(c)

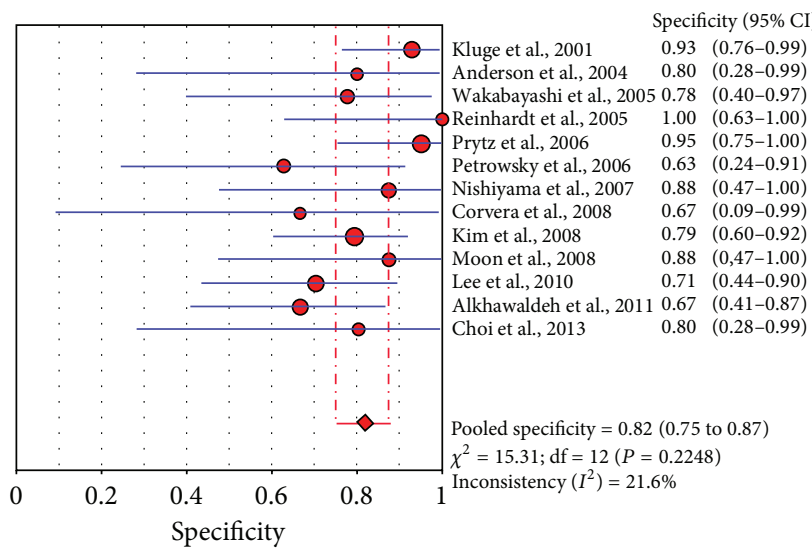

(b)

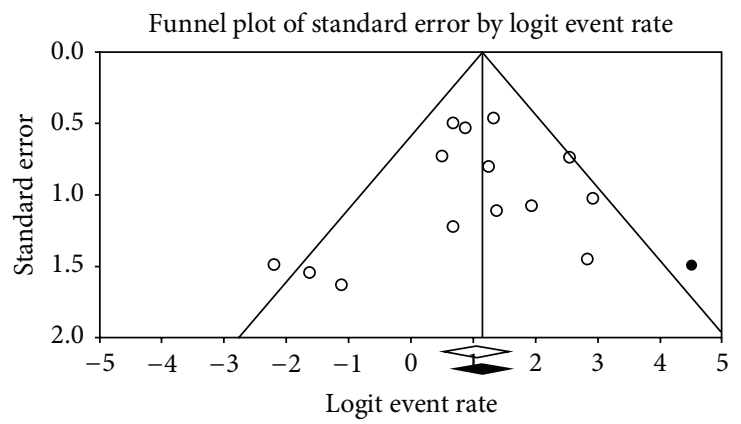

(d)

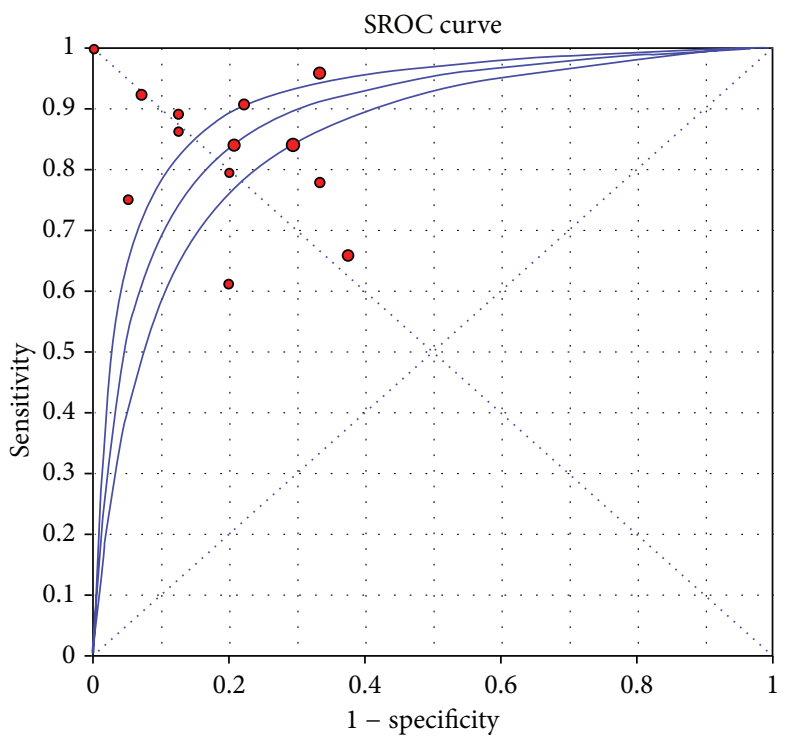

(e)

FIGURE 2: Plots of pooled sensitivity (a) and specificity (b), publication bias analysis for sensitivity (c) and specificity (d), and summary ROC curve (e) of ${ }^{18}$ F-FDG-PET or PET/CT in primary cholangiocarcinoma. 
TABLE 1: Basic characteristics of the included studies.

\begin{tabular}{|c|c|c|c|c|c|c|c|}
\hline Authors & Year & Country & Study design & $\begin{array}{l}\text { Patients performing } \\
{ }^{18} \text { F-FDG-PET or PET/CT }\end{array}$ & $\begin{array}{l}\text { Mean age } \\
\text { (years) }\end{array}$ & $\begin{array}{c}\text { Gender } \\
(\% \\
\text { male }) \\
\end{array}$ & $\begin{array}{l}\text { Site of primary } \\
\text { tumour }\end{array}$ \\
\hline Fritscher-Ravens et al. [6] & 2001 & Germany & Prospective & 15 & 58 & $60 \%$ & $15 \mathrm{H}-\mathrm{CCa}$ \\
\hline Kluge et al. [7] & 2001 & Germany & Prospective & 54 & NR & $54 \%$ & NR \\
\hline Kato et al. [8] & 2002 & Japan & NR & 30 & 68 & $70 \%$ & $30 \mathrm{EH}-\mathrm{CCa}$ \\
\hline Kim et al. [9] & 2003 & Korea & Retrospective & 21 & 57 & $52 \%$ & $\begin{array}{c}10 \mathrm{H}-\mathrm{CCa} \text { and } 11 \\
\mathrm{IH}-\mathrm{CCa}\end{array}$ \\
\hline Anderson et al. [10] & 2004 & USA & NR & 36 & 63 & $55 \%$ & NR \\
\hline Reinhardt et al. [11] & 2005 & Germany & NR & 20 & 63 & $50 \%$ & $20 \mathrm{H}-\mathrm{CCa}$ \\
\hline Wakabayashi et al. [12] & 2005 & Japan & Retrospective & 30 & 71 & $50 \%$ & $\begin{array}{c}5 \mathrm{IH}-\mathrm{CCa} \text { and } 25 \\
\mathrm{EH}-\mathrm{CCa}\end{array}$ \\
\hline Petrowsky et al. [13] & 2006 & Switzerland & Prospective & 61 & 64 & $51 \%$ & $\begin{array}{c}14 \mathrm{IH}-\mathrm{CCa} \text { and } 33 \\
\mathrm{EH}-\mathrm{CCa} \\
\end{array}$ \\
\hline Prytz et al. [14] & 2006 & Sweden & Prospective & 24 & 39 & $83 \%$ & NR \\
\hline Nishiyama et al. [15] & 2007 & Japan & Retrospective & 37 & 70 & $59 \%$ & $29 \mathrm{EH}-\mathrm{CCa}$ \\
\hline Corvera et al. [16] & 2008 & USA & Retrospective & 126 & 62 & $52 \%$ & $\begin{array}{c}41 \mathrm{EH}-\mathrm{CCa} \text { and } 21 \\
\text { IH-CCa }\end{array}$ \\
\hline Furukawa et al. [17] & 2008 & Japan & Prospective & 72 & 69 & $57 \%$ & $64 \mathrm{EH}-\mathrm{CCa}$ \\
\hline Kim et al. [18] & 2008 & Korea & Prospective & 123 & 60 & $65 \%$ & $\begin{array}{c}36 \mathrm{IH}-\mathrm{CCa} \text { and } 87 \\
\mathrm{EH}-\mathrm{CCa} \\
\end{array}$ \\
\hline Li et al. [19] & 2008 & Germany & Prospective & 17 & 62 & $65 \%$ & $17 \mathrm{H}-\mathrm{CCa}$ \\
\hline Moon et al. [20] & 2008 & Korea & Retrospective & 54 & 59 & $63 \%$ & $\begin{array}{c}23 \mathrm{IH}-\mathrm{CCa}, 12 \\
\mathrm{H}-\mathrm{CCa} \text {, and } 11 \\
\mathrm{EH}-\mathrm{CCa}\end{array}$ \\
\hline Lee et al. [21] & 2010 & Korea & Retrospective & 99 & 67 & $59 \%$ & $\begin{array}{c}17 \mathrm{IH}-\mathrm{CCa} \text { and } 49 \\
\mathrm{EH}-\mathrm{CCa}\end{array}$ \\
\hline Alkhawaldeh et al. [22] & 2011 & Germany & Retrospective & 65 & 63 & $60 \%$ & $\begin{array}{c}34 \mathrm{H}-\mathrm{CCa} \text { and } 23 \\
\text { IH-CCa }\end{array}$ \\
\hline Kitamura et al. [23] & 2011 & Japan & NR & 73 & 66 & $63 \%$ & $\begin{array}{c}45 \mathrm{H}-\mathrm{CCa} \text { and } 28 \\
\mathrm{EH}-\mathrm{CCa}\end{array}$ \\
\hline Ruys et al. [24] & 2011 & Netherlands & Retrospective & 30 & 62 & $47 \%$ & $26 \mathrm{H}-\mathrm{CCa}$ \\
\hline Yamada et al. [25] & 2012 & Japan & Retrospective & 73 & 68 & $63 \%$ & $\begin{array}{c}16 \mathrm{IH}-\mathrm{CCa}, 18 \\
\mathrm{H}-\mathrm{CCa} \text {, and } 20 \\
\mathrm{EH}-\mathrm{CCa}\end{array}$ \\
\hline Albazaz et al. [3] & 2013 & UK & Retrospective & 81 & 65 & $41 \%$ & $\begin{array}{c}47 \mathrm{IH}-\mathrm{CCa} \text { and } 34 \\
\mathrm{EH}-\mathrm{CCa} \\
\end{array}$ \\
\hline Choi et al. [1] & 2013 & Korea & Retrospective & 39 & 64 & $72 \%$ & 34 EH-CCa \\
\hline Lee et al. [2] & 2013 & Korea & Retrospective & 52 & 69 & $53 \%$ & $\begin{array}{c}23 \mathrm{EH}-\mathrm{CCa}, 17 \\
\mathrm{H}-\mathrm{CC} \text {, and } 12 \\
\text { IH-CCa }\end{array}$ \\
\hline
\end{tabular}

NR: not reported; H-CCa: hilar cholangiocarcinoma; EH-CCa: extrahepatic cholangiocarcinoma; IH-CCa: intrahepatic cholangiocarcinoma.

factors (such as the anatomical localization of the primary $\mathrm{CCa}$ ) seem to be a stronger source of heterogeneity. PET alone seems to be more specific than PET/CT (89\% and 75\%, resp.). A possible explanation of these surprising findings could be the higher number of patients with primary EH-CCa included in the studies which performed PET/CT compared to those which performed PET only.
Finally, regarding the diagnostic workup of patients with $\mathrm{CCa},{ }^{18}$ F-FDG-PET and PET/CT may have little diagnostic advantage over traditional imaging modalities in detecting the primary CCA [3]. ${ }^{18}$ F-FDG-PET and PET/CT can be complementary to $\mathrm{CT}$ and $\mathrm{MR}$ in the diagnosing and staging of CCA [20]. Since ${ }^{18}$ F-FDG-PET imaging is a wholebody scanning technique, it allows detection of unsuspected 


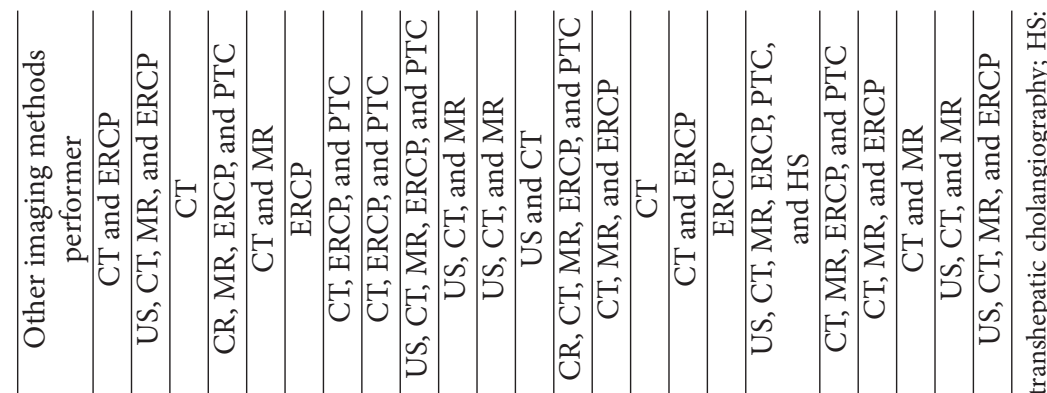

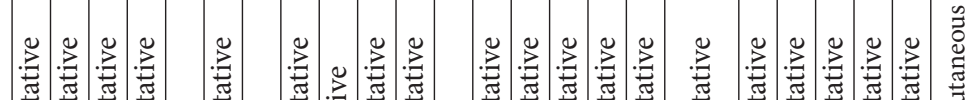

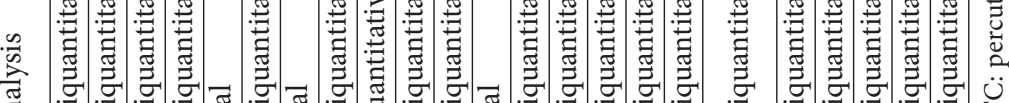

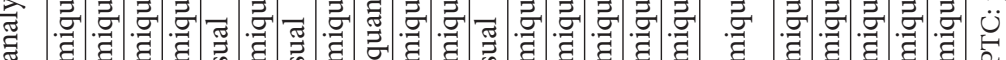

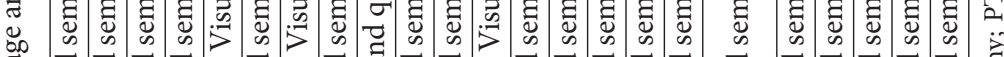

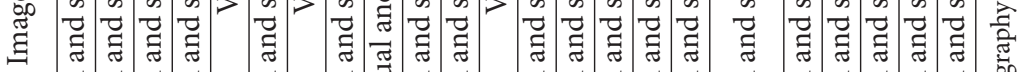

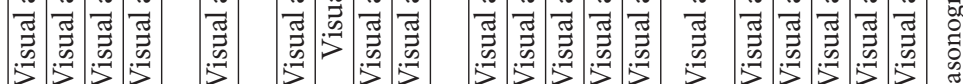

离

.ํํำ

$\stackrel{\square}{\square}:$

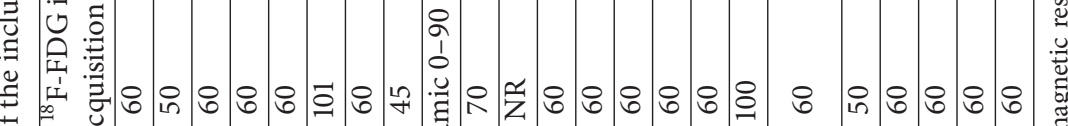

范

象

可

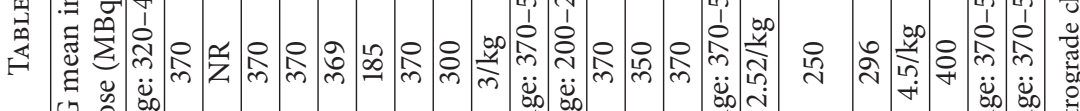
品 वे द्व 蛿

芯

品

品 苟

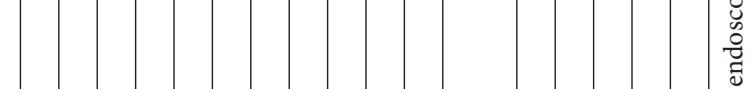

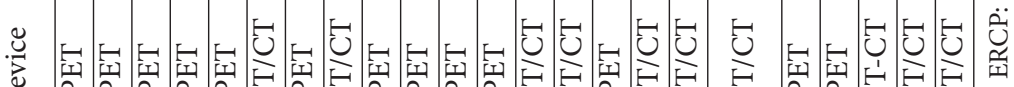

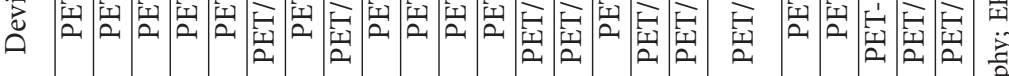

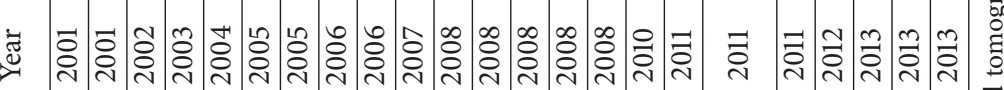

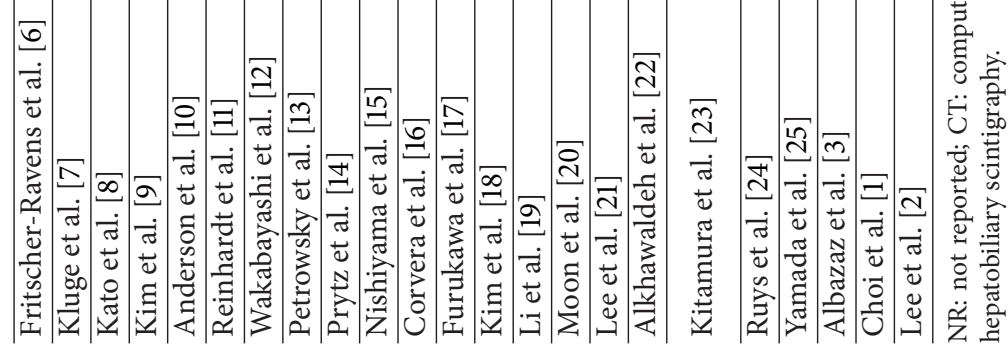




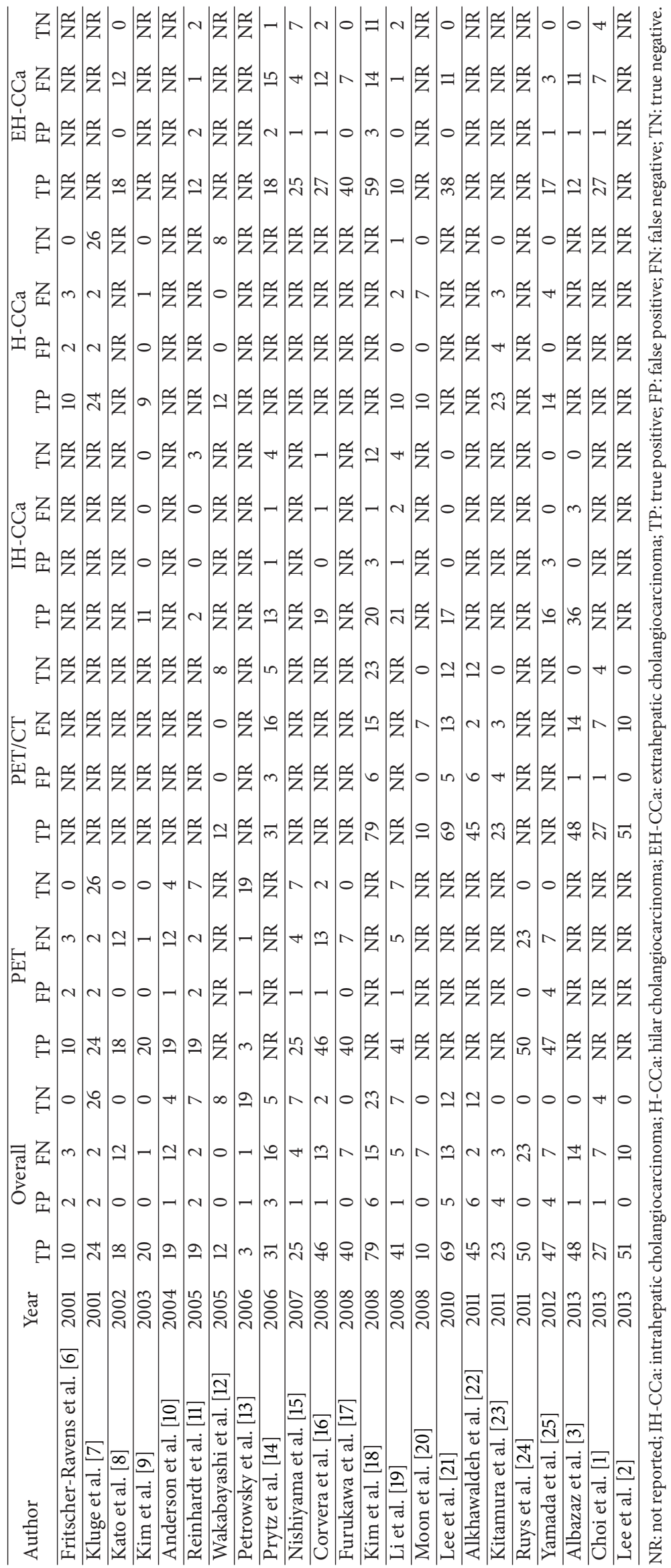




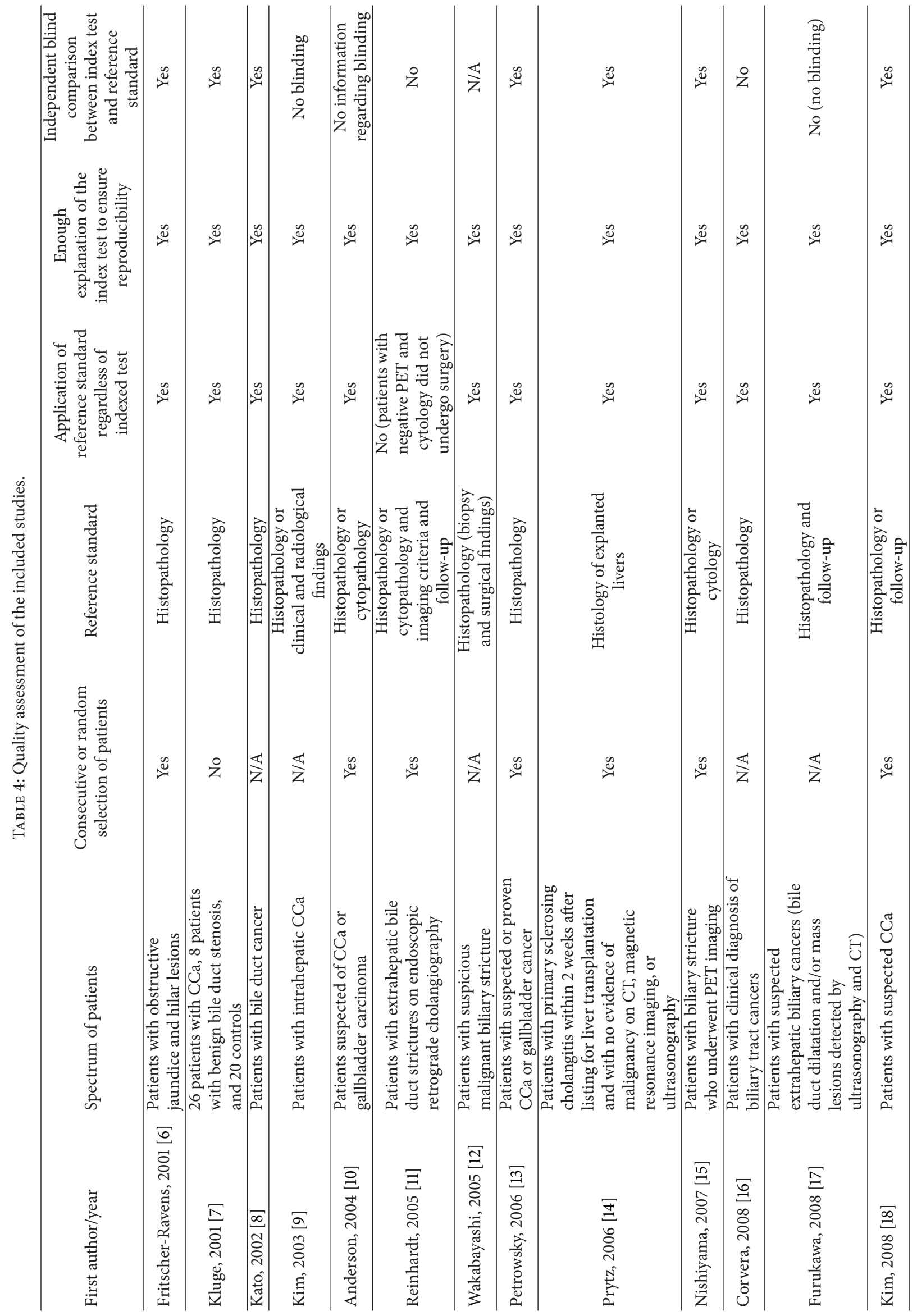




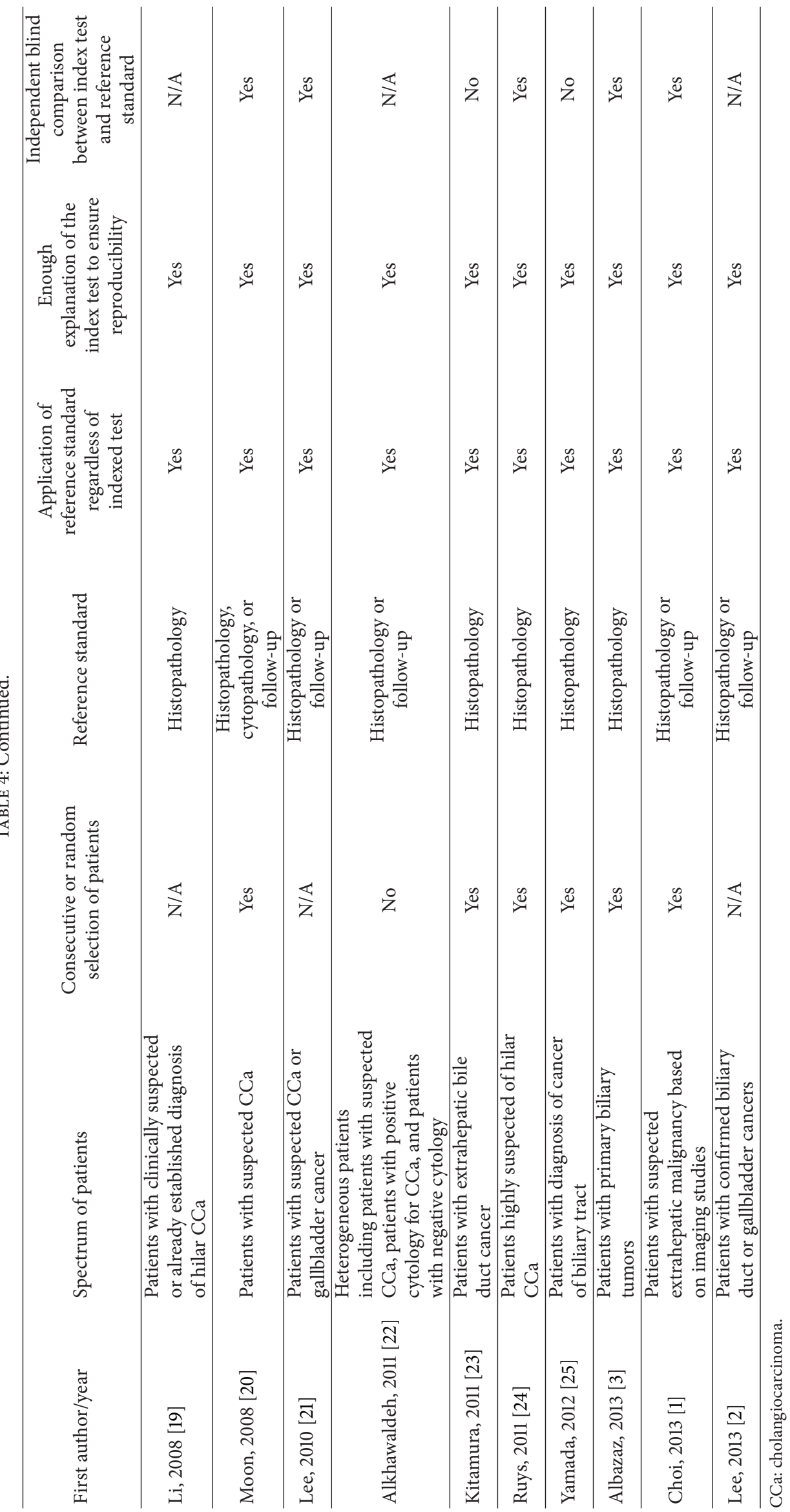




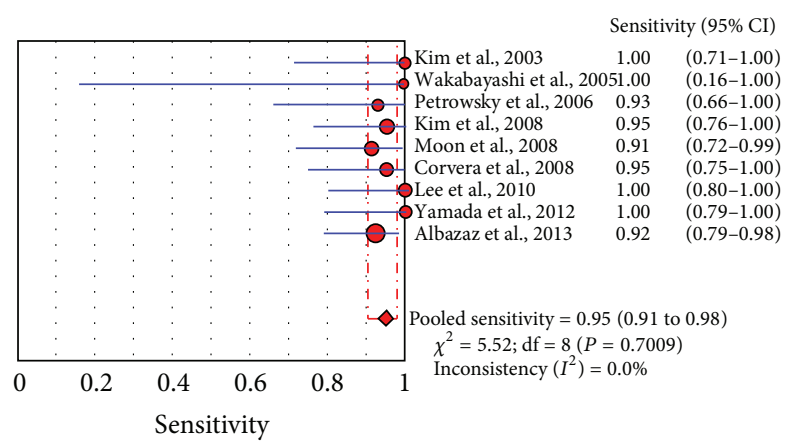

(a)

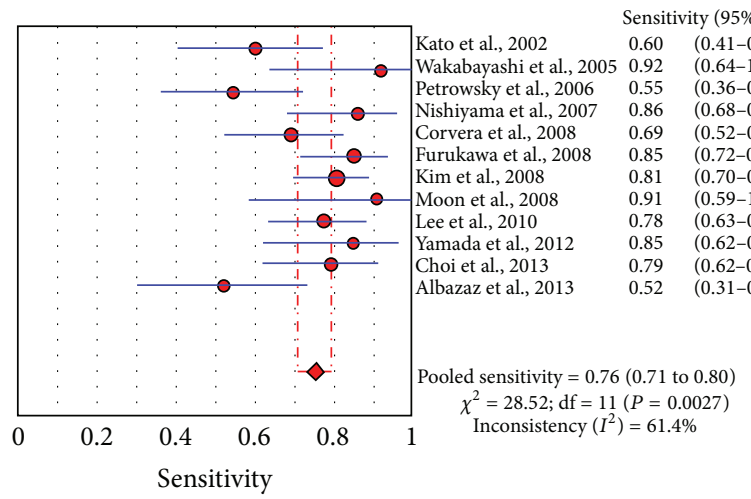

(c)

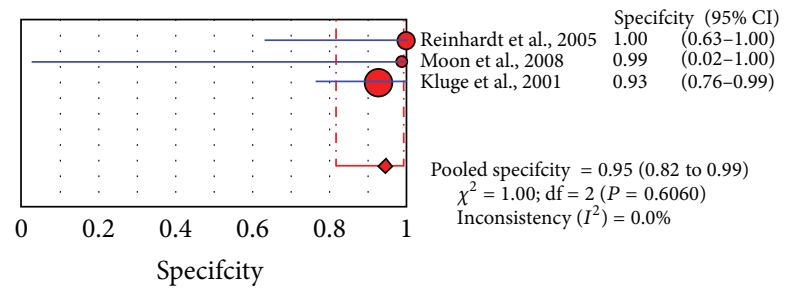

(e)

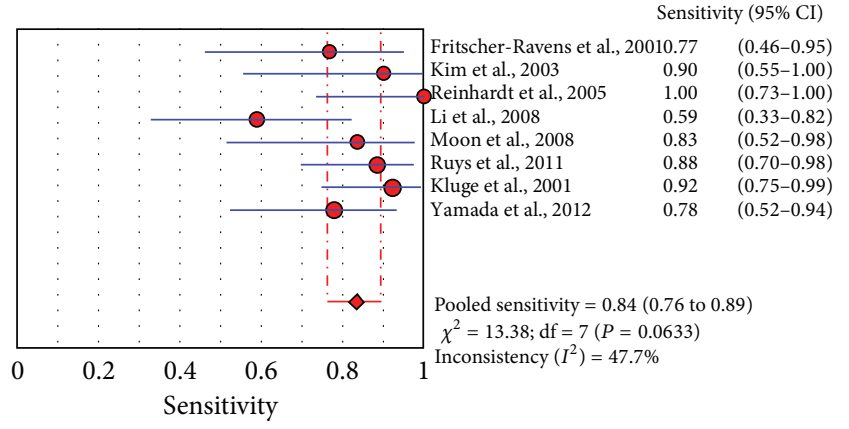

(b)

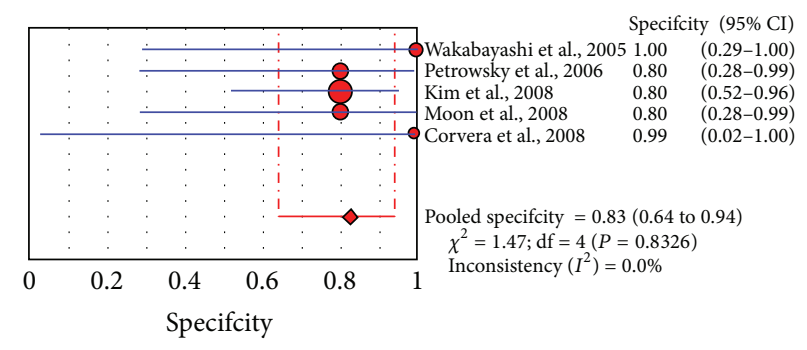

(d)

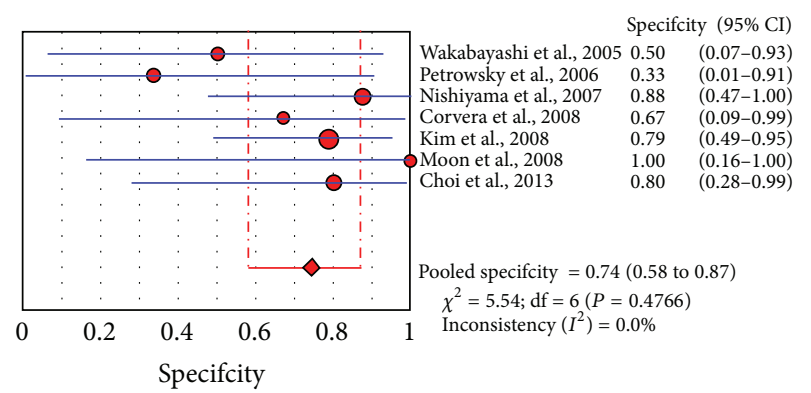

(f)

FIGURE 3: Plots of pooled sensitivity and specificity of ${ }^{18}$ F-FDG-PET or PET/CT in primary intrahepatic cholangiocarcinoma ((a), (d)), hilar cholangiocarcinoma ((b), (e)), and extrahepatic cholangiocarcinoma ((c), (f)).

metastatic lymph nodes or distant spread that may lead to major changes in the surgical management of patients with biliary tract cancer [25]. Nevertheless, the diagnostic performance of ${ }^{18} \mathrm{FDG}$-PET or PET/CT in detecting metastatic lymph nodes or distant spread was not object of our analysis.

This study has several limitations. Different anatomical classifications of CCa were used by several studies. For example, it is likely that some H-CCa were classified as EHCCa by some studies. Other possible limitations of our metaanalysis could be the heterogeneity between the included studies (nevertheless subgroup analyses were performed to reduce the heterogeneity) and the possible publication bias. We assessed publication bias in our meta-analysis using qualitative and quantitative methods (Egger's regression and
Duval and Tweedie's method). Funnel plots showed the importance of possible publication bias in particular for the estimation of pooled sensitivity (Figure 2).

Overall, ${ }^{18}$ F-FDG-PET and PET/CT were demonstrated to be accurate noninvasive tools in the evaluation of primary tumors in patients with CCa. Furthermore, more studies in patients with $\mathrm{H}-\mathrm{CCa}$ and cost-effectiveness analyses of the role of ${ }^{18} \mathrm{~F}$-FDG-PET or PET/CT in this setting are needed.

\section{Conclusions}

${ }^{18} \mathrm{~F}$-FDG-PET and PET/CT were demonstrated to be accurate diagnostic imaging methods in the evaluation of primary tumors in patients with CCa. These tools seem to have 


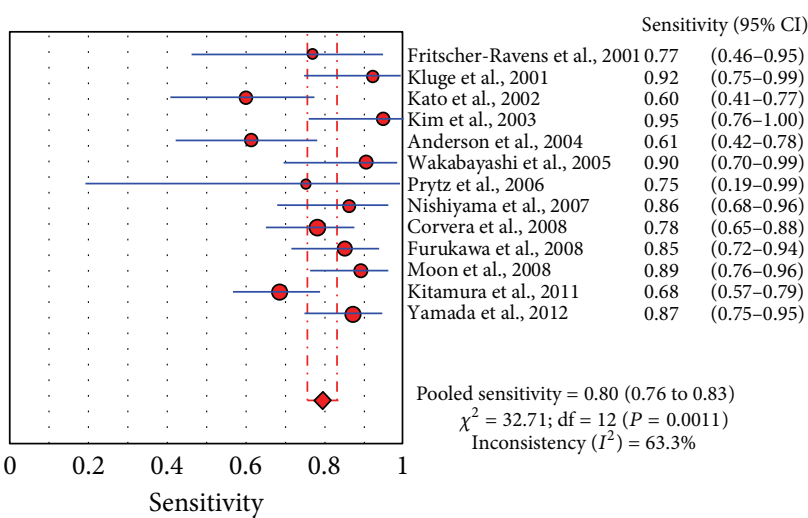

(a)

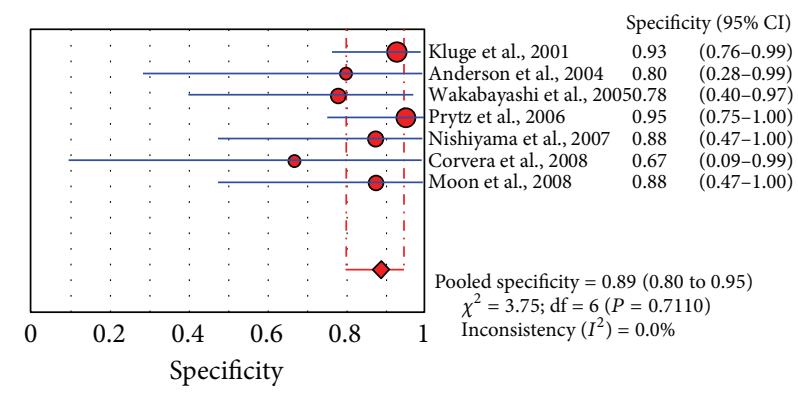

(c)

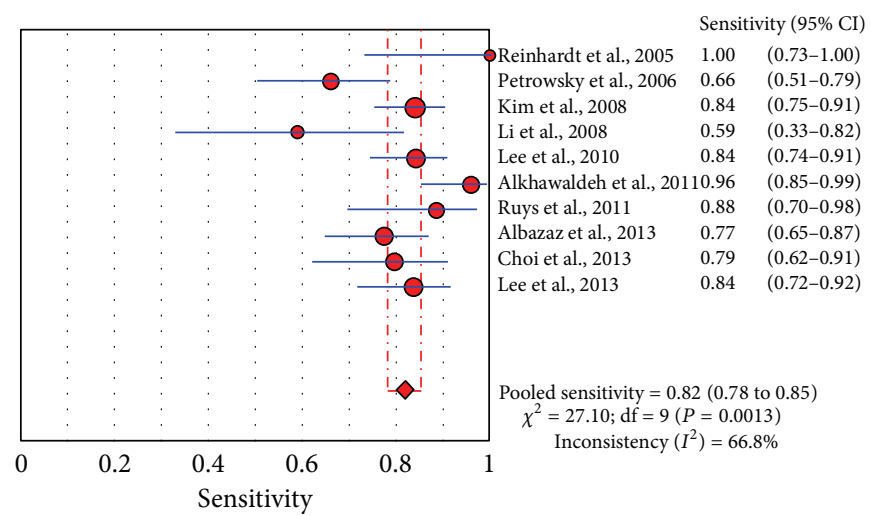

(b)

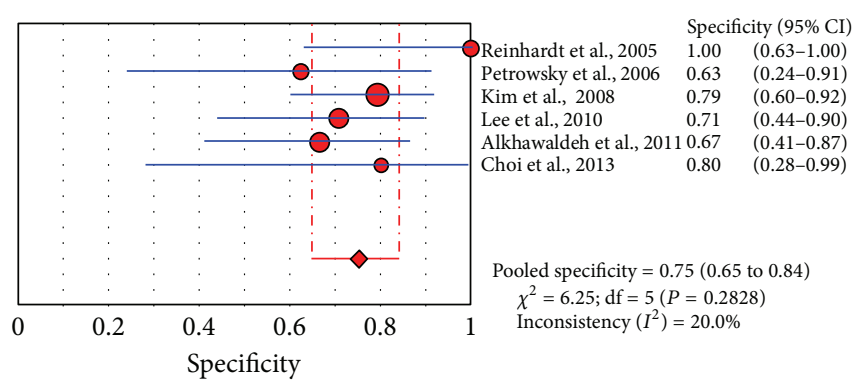

(d)

FIGURE 4: Plots of pooled sensitivity and specificity of ${ }^{18}$ F-FDG-PET ((a), (c)) or PET/CT ((b), (d)) in primary cholangiocarcinoma.

a better diagnostic accuracy in the evaluation of primary IH-CCa compared to EH-CCa. Further studies are needed to evaluate the accuracy of ${ }^{18} \mathrm{~F}-\mathrm{FDG}-\mathrm{PET}$ and PET/CT in assessing primary $\mathrm{H}-\mathrm{CCa}$.

\section{Conflict of Interests}

The authors declare that they have no conflict of interests.

\section{Acknowledgment}

This manuscript was written by using ABREOC funding from the Oncology Institute of Southern Switzerland.

\section{References}

[1] E. K. Choi, Y. IeR, S. H. Kim et al., "The clinical value of dualtime point ${ }^{18}$ F-FDG PET/CT for differentiating extrahepatic cholangiocarcinoma from benign disease," Clinical Nuclear Medicine, vol. 38, pp. e106-e111, 2013.

[2] J. Y. Lee, H. J. Kim, S. H. Yim et al., "Primary tumor maximum standardized uptake value measured on ${ }^{18} \mathrm{~F}$ fluorodeoxyglucose positron emission tomography-computed tomography is a prognostic value for survival in bile duct and gallbladder cancer," The Korean Journal of Gastroenterology, vol. 62, pp. 227-233, 2013.

[3] R. Albazaz, C. N. Patel, F. U. Chowdhury, and A. F. Scarsbrook, "Clinical impact of FDG PET-CT on management decisions for patients with primary biliary tumours," Insights Imaging, vol. 4, pp. 691-700, 2013.
[4] G. Treglia, E. Cason, and G. Fagioli, "Recent applications of nuclear medicine in diagnostics (first part)," Italian Journal of Medicine, vol. 4, no. 2, pp. 84-91, 2010.

[5] M. Egger, G. D. Smith, M. Schneider, and C. Minder, "Bias in meta-analysis detected by a simple, graphical test," British Medical Journal, vol. 315, no. 7109, pp. 629-634, 1997.

[6] A. Fritscher-Ravens, K. H. Bohuslavizki, D. C. Broering et al., "FDG PET in the diagnosis of hilar cholangiocarcinoma," Nuclear Medicine Communications, vol. 22, no. 12, pp. 12771285, 2001.

[7] R. Kluge, F. Schmidt, K. Caca et al., "Positron emission tomography with $\left[{ }^{18} \mathrm{~F}\right]$ fluoro-2-deoxyd-D-glucose for diagnosis and staging of bile duct cancer," Hepatology, vol. 33, no. 5, pp. 1029$1035,2001$.

[8] T. Kato, E. Tsukamoto, Y. Kuge et al., "Clinical role of ${ }^{18}$ F-FDG PET for initial staging of patients with extrahepatic bile duct cancer," European Journal of Nuclear Medicine, vol. 29, no. 8, pp. 1047-1054, 2002.

[9] Y.-J. Kim, M. Yun, W. J. Lee, K. S. Kim, and J. D. Lee, "Usefulness of ${ }^{18}$ F-FDG PET in intrahepatic cholangiocarcinoma," European Journal of Nuclear Medicine and Molecular Imaging, vol. 30, no. 11, pp. 1467-1472, 2003.

[10] C. D. Anderson, M. H. Rice, C. W. Pinson, W. C. Chapman, R. S. Chari, and D. Delbeke, "Fluorodeoxyglucose PET imaging in the evaluation of gallbladder carcinoma and cholangiocarcinoma," Journal of Gastrointestinal Surgery, vol. 8, no. 1, pp. 9097, 2004.

[11] M. J. Reinhardt, H. Strunk, T. Gerhardt et al., "Detection of Klatskin's tumor in extrahepatic bile duct strictures using delayed ${ }^{18}$ F-FDG PET/CT: preliminary results for 22 patient 
studies," Journal of Nuclear Medicine, vol. 46, no. 7, pp. 11581163, 2005.

[12] H. Wakabayashi, S. Akamoto, S. Yachida et al., "Significance of fluorodeoxyglucose PET imaging in the diagnosis of malignancies in patients with biliary stricture," European Journal of Surgical Oncology, vol. 31, no. 10, pp. 1175-1179, 2005.

[13] H. Petrowsky, P. Wildbrett, D. B. Husarik et al., "Impact of integrated positron emission tomography and computed tomography on staging and management of gallbladder cancer and cholangiocarcinoma," Journal of Hepatology, vol. 45, no. 1, pp. 43-50, 2006.

[14] H. Prytz, S. Keiding, E. Björnsson et al., "Dynamic FDG-PET is useful for detection of cholangiocarcinoma in patients with PSC listed for liver transplantation," Hepatology, vol. 44, no. 6, pp. 1572-1580, 2006.

[15] Y. Nishiyama, Y. Yamamoto, N. Kimura et al., "Comparison of early and delayed FDG PET for evaluation of biliary stricture," Nuclear Medicine Communications, vol. 28, no. 12, pp. 914-919, 2007.

[16] C. U. Corvera, L. H. Blumgart, T. Akhurst et al., " ${ }^{18} \mathrm{~F}-$ fluorodeoxyglucose positron emission tomography influences management decisions in patients with biliary cancer," Journal of the American College of Surgeons, vol. 206, no. 1, pp. 57-65, 2008.

[17] H. Furukawa, H. Ikuma, K. Asakura-Yokoe, and K. Uesaka, "Preoperative staging of biliary carcinoma using ${ }^{18} \mathrm{~F}$ fluorodeoxyglucose PET: prospective comparison with PET+CT, MDCT and histopathology," European Radiology, vol. 18, no. 12, pp. 2841-2847, 2008.

[18] J. Y. Kim, M.-H. Kim, T. Y. Lee et al., "Clinical role of ${ }^{18} \mathrm{~F}-$ FDG PET-CT in suspected and potentially operable cholangiocarcinoma: a prospective study compared with conventional imaging," American Journal of Gastroenterology, vol. 103, no. 5, pp. 1145-1151, 2008.

[19] J. Li, H. Kuehl, F. Grabellus et al., "Preoperative assessment of hilar cholangiocarcinoma by dual-modality PET/CT,' Journal of Surgical Oncology, vol. 98, no. 6, pp. 438-443, 2008.

[20] C. M. Moon, S. Bang, J. B. Chung et al., "Usefulness of ${ }^{18} \mathrm{~F}-$ fluorodeoxyglucose positron emission tomography in differential diagnosis and staging of cholangiocarcinomas," Journal of Gastroenterology and Hepatology, vol. 23, no. 5, pp. 759-765, 2008.

[21] S. W. Lee, H. J. Kim, J. H. Park et al., "Clinical usefulness of ${ }^{18}$ F-FDG PET-CT for patients with gallbladder cancer and cholangiocarcinoma," Journal of Gastroenterology, vol. 45, no. 5, pp. 560-566, 2010.

[22] K. Alkhawaldeh, S. Faltten, H.-J. Biersack, and S. Ezziddin, "The value of F-18 FDG PET in patients with primary sclerosing cholangitis and cholangiocarcinoma using visual and semiquantitative analysis," Clinical Nuclear Medicine, vol. 36, no. 10, pp. 879-883, 2011.

[23] K. Kitamura, E. Hatano, T. Higashi et al., "Prognostic value of ${ }^{18} \mathrm{~F}$-fluorodeoxyglucose positron emission tomography in patients with extrahepatic bile duct cancer," Journal of HepatoBiliary-Pancreatic Sciences, vol. 18, no. 1, pp. 39-46, 2011.

[24] A. T. Ruys, R. J. Bennink, H. L. Van Westreenen et al., "FDG-positron emission tomography/computed tomography and standardized uptake value in the primary diagnosis and staging of hilar cholangiocarcinoma," $H P B$, vol. 13 , no. 4, pp. 256-262, 2011.
[25] I. Yamada, T. Ajiki, K. Ueno et al., "Feasibility of (18)Ffluorodeoxyglucose positron-emission tomography for preoperative evaluation of biliary tract cancer," Anticancer Research, vol. 32, pp. 5105-5110, 2012.

[26] G. Treglia and R. Sadeghi, "Meta-analyses and systematic reviews on PET and PET/CT in oncology: the state of the art," Clinical and Translational Imaging, vol. 1, pp. 73-75, 2013. 


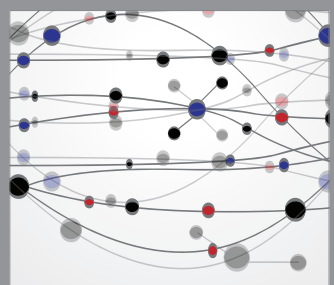

The Scientific World Journal
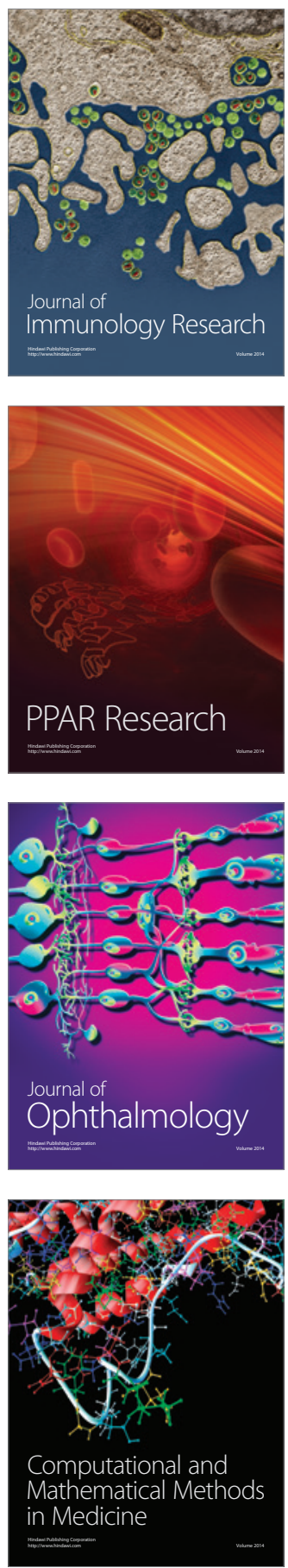

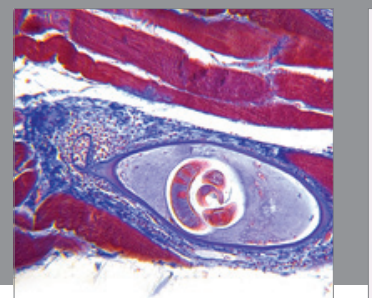

Gastroenterology

Research and Practice
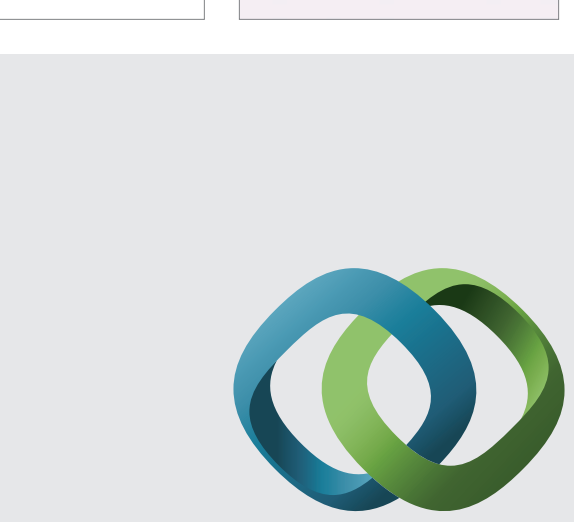

\section{Hindawi}

Submit your manuscripts at

http://www.hindawi.com
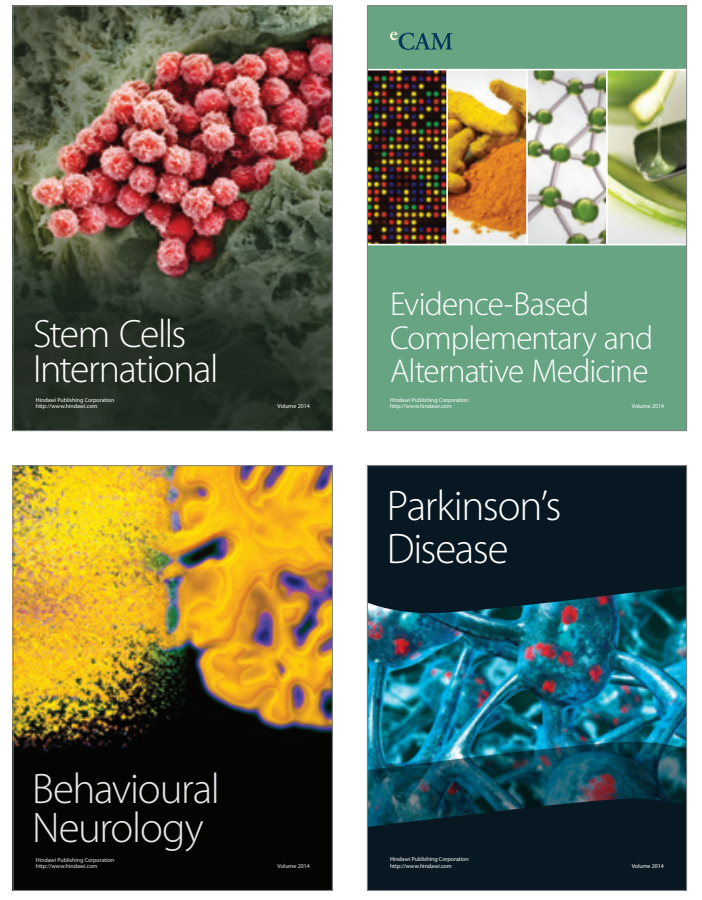
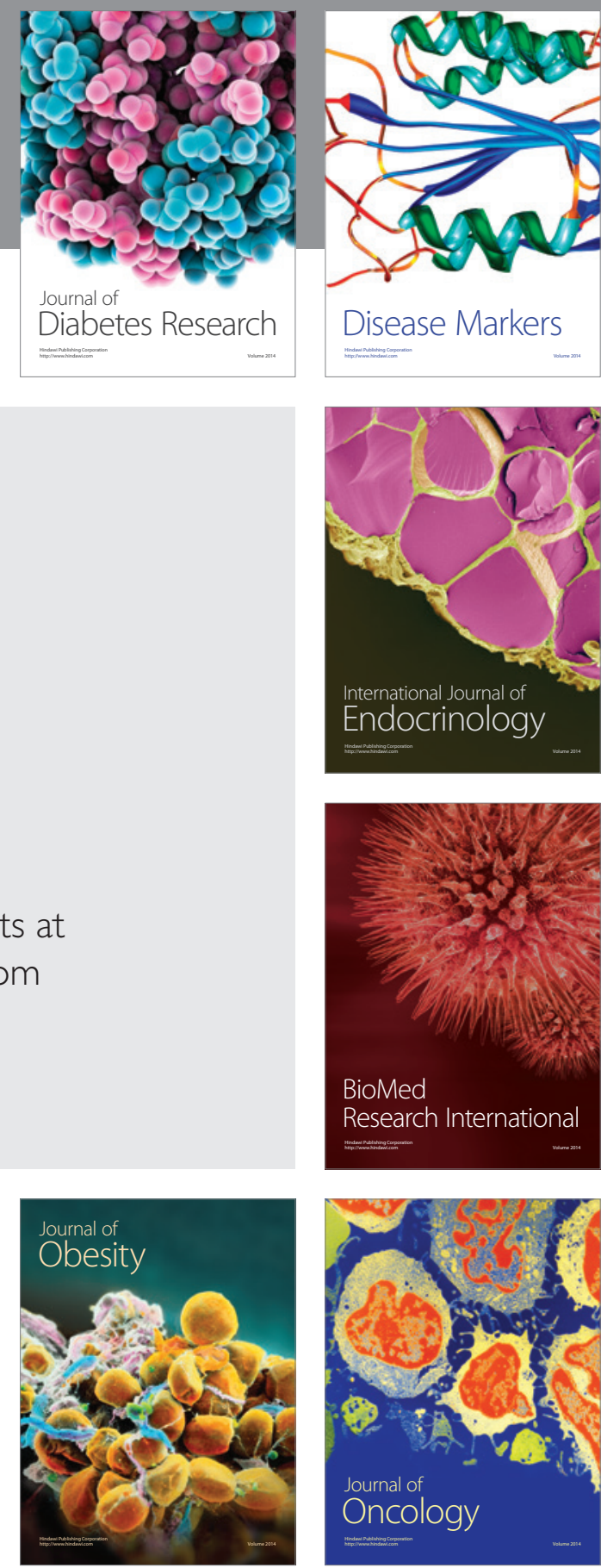

Disease Markers
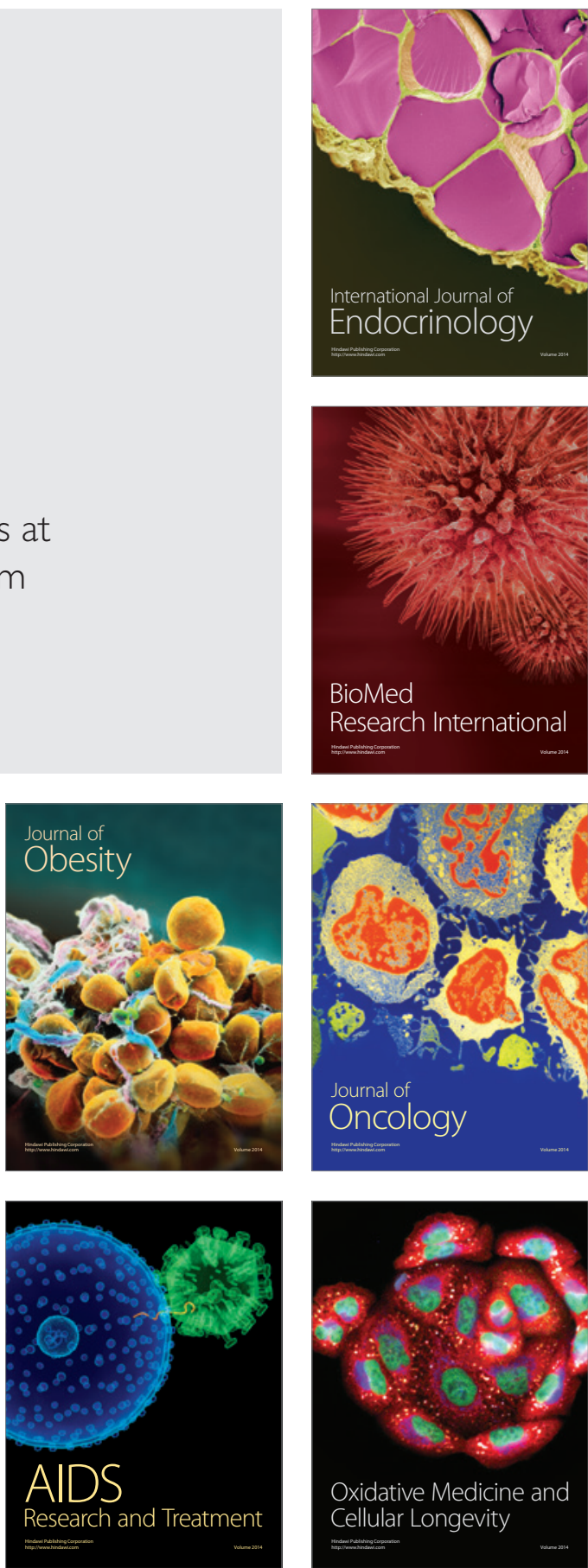